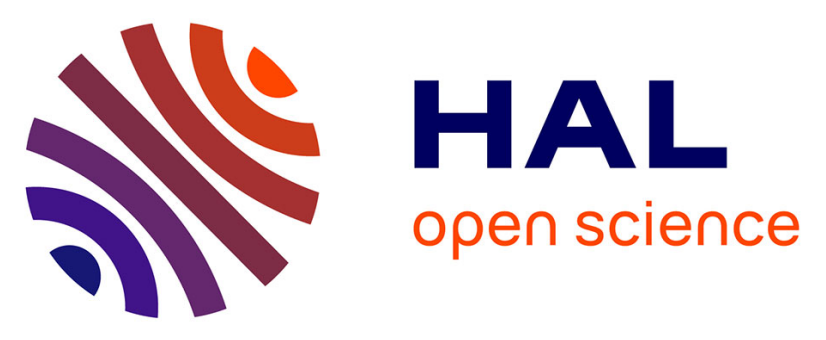

\title{
The role of NH $4+$ cations on the electrochemistry of Prussian Blue studied by electrochemical, mass, and color impedance spectroscopy
}

Jeronimo Agrisuelas, C. Delgado, Claude Gabrielli, J. J. García-Jareño, Hubert Perrot, Ozlem Sel, F. Vicente

\section{To cite this version:}

Jeronimo Agrisuelas, C. Delgado, Claude Gabrielli, J. J. García-Jareño, Hubert Perrot, et al.. The role of NH $4+$ cations on the electrochemistry of Prussian Blue studied by electrochemical, mass, and color impedance spectroscopy. Journal of Solid State Electrochemistry, 2015, 19 (9), pp.2555-2564. $10.1007 / \mathrm{s} 10008-015-2806-y$. hal-01224127

\section{HAL Id: hal-01224127 \\ https: / hal.sorbonne-universite.fr/hal-01224127}

Submitted on 4 Nov 2015

HAL is a multi-disciplinary open access archive for the deposit and dissemination of scientific research documents, whether they are published or not. The documents may come from teaching and research institutions in France or abroad, or from public or private research centers.
L'archive ouverte pluridisciplinaire HAL, est destinée au dépôt et à la diffusion de documents scientifiques de niveau recherche, publiés ou non, émanant des établissements d'enseignement et de recherche français ou étrangers, des laboratoires publics ou privés. 
The role of $\mathrm{NH}_{4}^{+}$cations on the electrochemistry of Prussian Blue studied by electrochemical, mass and color impedance spectroscopy

J. Agrisuelas ${ }^{1}$, C. Delgado ${ }^{1}$, C. Gabrielli ${ }^{2,3}$, J.J. García-Jareño ${ }^{1}$, H. Perrot ${ }^{2,3}$, O.Sel $^{2,3}$ and F. Vicente ${ }^{1}$

1 Departament de Química Física, Universitat de València. C/ Dr. Moliner, 50, 46100, Burjassot, València, Spain.

${ }^{2}$ Sorbonne Universités, UPMC Univ Paris 06, UMR 8235, Laboratoire Interfaces et Systèmes Electrochimiques, F-75005, Paris, France.

${ }^{3}$ CNRS, UMR 8235, LISE, F-75005, Paris, France. 


\begin{abstract}
The role of the ammonium cation on the reversible electrochemistry of Prussian Blue thin films was analyzed through in situ combination of three different impedance techniques. Electrochemical impedance spectroscopy provides information on the electron transfer. Mass impedance spectroscopy allows the exchange of free water, ammonium and proton ions to be elucidated. Color impedance spectroscopy provides the kinetics of electrochromic changes of Prussian Blue structure (main backbone structure, ferrocyanide vacancies and trapped structures). The simultaneous measurement of the three impedances gives detailed information on the mechanism of the whole process, specifically one faster and two slower, which have been identified during the electrochemical reactions of Prussian Blue films in $\mathrm{NH}_{4} \mathrm{Cl}$ acidic solutions.
\end{abstract}

Keywords: Prussian Blue; ammonium cation; electrochemical impedance spectroscopy; mass impedance spectroscopy; color impedance spectroscopy. 


\section{Introduction}

Prussian Blue ( $\mathrm{PB}$, ferric ferrocyanide) is a well-known inorganic electrochromic compound which can easily be electrodeposited on various types of electrode substrates[1, 2]. The good stability of PB films and other metal ferrocyanide analogs makes these materials the subject of many electrochemical studies and many interesting technological applications going from sensors to batteries $[3,4]$.

In particular, $\mathrm{PB}$ films freshly electrodeposited from equimolar solutions of $\mathrm{K}_{3} \mathrm{Fe}(\mathrm{CN})_{6}$ and $\mathrm{FeCl}_{3}$ correspond to the mixed valence form of $\mathrm{Fe}^{\mathrm{III}} / \mathrm{Fe}^{\mathrm{II}}[5,6]$. The oxidation state of $\mathrm{PB}$ can finely be controlled by an external source of potential. The films can be reduced to the colorless Everitt's salt form (ES, $\mathrm{Fe}^{\mathrm{II}} / \mathrm{Fe}^{\mathrm{II}}$ ) or oxidized to the Prussian Yellow form (PY, $\left.\mathrm{Fe}^{\mathrm{III}} / \mathrm{Fe}^{\mathrm{III}}\right)$. These electrochemical reactions involve the exchange of counterions to keep the electroneutrality of the films during the charge balance processes [7, 8]. Predominantly, electrogravimetric studies have proved that this balance takes place by cation exchanges $[9$, $10]$.

Initially, the structure of freshly prepared PB films has been described as a $\mathrm{K}^{+}$free structure and therefore, a direct PB oxidation to form PY films results in the structure breakdown of the films [11]. However, if freshly prepared PB films were previously cycled around the $\mathrm{PB} \rightleftarrows \mathrm{ES}$ system by cyclic voltammetry, $\mathrm{K}^{+}$cations occupy key position in the inner structure of PB and then, the oxidation to the PY form can take place without destruction of the films $[5,7,12-14]$. Once PB films are stabilized in acid $\mathrm{KCl}$ solutions by cyclic voltammetry, the voltammetric peaks of the $\mathrm{PB} \rightleftarrows \mathrm{ES}$ system appear to be stable after hundred and even thousands of cycles [15]. In recent papers $[13,14]$, the stable PB structure has been described as $\mathrm{Fe}_{4}^{3+}\left[\mathrm{Fe}^{2+}(\mathrm{CN})_{6}\right]_{3} \cdot\left[\left(\mathrm{K}^{+}\right)_{2} \cdot\left(\mathrm{OH}^{-}\right)_{2} \cdot\left(\mathrm{mH}_{2} \mathrm{O}\right)\right]_{3}$. The $\mathrm{PB} \rightleftarrows \mathrm{ES}$ system has been studied by mass impedance spectroscopy and the role of potassium cations has been elucidated $[9,16,17]$ :

$$
\begin{gathered}
\mathrm{Fe}_{4}^{3+}\left[\mathrm{Fe}^{2+}(\mathrm{CN})_{6}\right]_{3} \cdot\left[\left(\mathrm{K}^{+}\right)_{2} \cdot\left(\mathrm{OH}^{-}\right)_{2} \cdot\left(\mathrm{mH}_{2} \mathrm{O}\right)\right]_{3}+4 \mathrm{~K}^{+}+4 \mathrm{e}^{-} \\
\rightleftarrows \mathrm{K}_{4} \mathrm{Fe}_{4}^{2+}\left[\mathrm{Fe}^{2+}(\mathrm{CN})_{6}\right]_{3} \cdot\left[\left(\mathrm{K}^{+}\right)_{2} \cdot\left(\mathrm{OH}^{-}\right)_{2} \cdot\left(\mathrm{mH}_{2} \mathrm{O}\right)\right]_{3}
\end{gathered}
$$

On the contrary, the PB $\rightleftarrows \mathrm{PY}$ system is not perfectly described and the participation of counterions is more complicated. The structure change can hinder the exchange of cations during this redox process. Previously, this process was described with the exclusive participation of anions as counterions [2]. However, electrogravimetric results showed a decrease of mass during the oxidation of PB to the PY form, and an increase of the mass during the reverse reaction $(\mathrm{PY} \rightarrow \mathrm{PB})$ indicating the participation of cations [10]. According to the 
structure proposed here, there are only two $\mathrm{K}^{+}$cations for three $\mathrm{Fe}^{2+}$ sites. This means that there are not enough cations within the PB film to be expelled during the balance of the electric charge associated to the oxidation of the three iron atoms per unit cell. Thus, the participation of another cation (hydronium) or anion is necessary during the $\mathrm{PB} \rightarrow \mathrm{PY}$ process. As a consequence, $\mathrm{PB} \rightleftarrows \mathrm{PY}$ system shows a low electrochemical response. Recently, a possible reaction scheme for the $\mathrm{PB} \rightleftarrows \mathrm{PY}$ system has been proposed involving both cations and anions [14]:

$$
\begin{aligned}
& \mathrm{Fe}_{4}^{3+}\left[\mathrm{Fe}^{2+}(\mathrm{CN})_{6}\right]_{3} \cdot\left[\left(\mathrm{K}^{+}\right)_{2} \cdot\left(\mathrm{OH}^{-}\right)_{2} \cdot\left(\mathrm{mH}_{2} \mathrm{O}\right)\right]_{3}+\mathrm{A}^{-} \\
& \rightleftarrows \mathrm{Fe}_{4}^{3+}\left[\mathrm{Fe}^{3+}(\mathrm{CN})_{6}\right]_{3} \cdot\left[\mathrm{A}^{-} \cdot\left(\mathrm{OH}^{-}\right)_{2} \cdot\left(\mathrm{mH}_{2} \mathrm{O}\right)\right]_{3}+2 \mathrm{~K}^{+}
\end{aligned}
$$

After a voltammetric stabilization in $\mathrm{KCl}$ acid solution, the counter ions, which participate during the electrochemical reactions of the PB films, can be exchanged using different bathing solutions $[7,18,19]$. In the case of $\mathrm{NH}_{4}^{+}$cations, voltammograms show two well-defined voltammetric peaks, but the anodic peak appears wider and smaller than that observed in the case of $\mathrm{K}^{+}$transfer. Another interesting difference is observed during the oxidation process ( $\mathrm{PB} \rightleftarrows \mathrm{PY}$ ), where the voltammetric peaks appear much smaller than theses ones observed in the presence of $\mathrm{K}^{+}$cations $[18,19]$. Thus, $\mathrm{NH}_{4}^{+}$should play an important role during these electrochemical processes.

The aim of this paper is to elucidate the role of $\mathrm{NH}_{4}^{+}$during the electrochemical processes of $\mathrm{PB}$ films in a $0.5 \mathrm{M} \mathrm{NH}_{4} \mathrm{Cl}$ acid solution. For that, the $\mathrm{PB} \rightleftarrows \mathrm{ES}$ system was investigated by impedance spectroscopy. Today, the impedance spectroscopy can be used to study any analogic signals susceptible to be sinusoidally modulated and properly analyzed by a frequency response analyzer. Through a perusal of the literature, one can find studies of the conducting films by color impedance spectroscopy or CIS [20-25], mass impedance spectroscopy or MIS (the ac-electrogravimetry) [9, 26-30] or both of them together with electrochemical impedance spectroscopy (EIS) [16, 17, 31, 32]. The coupling of various impedance data has proved to be of special interest for studying the electrochemical response of conducting films. The electron transfer, counterions exchange and color changes which take place during the electrochemical reaction of conducting films can be deconvoluted from the global response by their time constant to obtain kinetic information [9, 33, 34]. Here, the in situ combination of electrochemical impedance spectroscopy (EIS), mass impedance spectroscopy (MIS) and color impedance spectroscopy (CIS) was used to study PB films at two characteristic wavelengths $(690 \mathrm{~nm}$ and $900 \mathrm{~nm})$. 


\section{Experimental}

Following the procedure described by Itaya et al. [2], PB was deposited from $0.02 \mathrm{M}$ $\mathrm{K}_{3}\left(\mathrm{Fe}(\mathrm{CN})_{6}\right)_{3}, 0.02 \mathrm{M} \mathrm{FeCl}_{3}$ and $0.01 \mathrm{M} \mathrm{HCl}$ freshly prepared solutions by applying a controlled cathodic current of $40 \mu \mathrm{A} \mathrm{cm}^{-2}$ during $150 \mathrm{~s}$. Afterwards, the modified electrode was stabilized by cyclic voltammetry between $0.6 \mathrm{~V}$ and $-0.2 \mathrm{~V}$ vs $\mathrm{Ag}|\mathrm{AgCl}| \mathrm{KCl}_{\text {sat }}$ (around the $\mathrm{PB} \rightleftarrows \mathrm{ES}$ ) in a $0.5 \mathrm{M} \mathrm{NH}_{4} \mathrm{Cl}$ solution at $\mathrm{pH}=3.0$. The $\mathrm{pH}$ of solution was adjusted with the addition of an appropriated amount of $1 \mathrm{M} \mathrm{HCl}$. For impedance experiments, the same solution was used. All chemicals used were analytical reagent quality obtained from Scharlau ${ }^{\mathrm{TM}}$.

The electrochemical cell was a $2 \times 2 \mathrm{~cm}$ optical glass cell where the auxiliary electrode was a platinum wire and an $\mathrm{Ag}|\mathrm{AgCl}| \mathrm{KCl}_{\text {sat }}$ electrode (RE-1C, Bas Inc., Japan) which all potentials are referred. The working electrode was a high reflectance gold electrode (AT cut quartz crystal, $6 \mathrm{MHz}$ Matel-Fordahl, France). All solutions were previously deaerated by bubbling argon for 10 minutes before the experiments, keeping an atmosphere of argon during the experiments. Temperature was controlled by means of a lab made Peltier temperature controller.

The experimental set-up and equipment required to simultaneously obtain the three impedance data have been described extensively in a previous work [32]. A PAR 263A galvanostat-potentiostat (Float and 98 options installed) together with a four-channel frequency response analyzer Solartron 1254 were used. A quartz crystal microbalance built at UMR 8235, CNRS (Paris, France), and a modified Vis-NIR spectrometer Spectronic 20+ with a silicon PIN photodiode OSD 100-6 (Centronic) were used to measure the mass impedance as $\Delta m / \Delta E(\omega)$ transfer function and the color impedance as $\Delta A^{\lambda} / \Delta E(\omega)$ transfer function, respectively. The impedance data are recorded in the frequency range from $10 \mathrm{kHz}$ to $0.01 \mathrm{~Hz}$, with 5 points per decade. The amplitude of the potential perturbation was $25 \mathrm{mV}$ rms.

The fitting of experimental data to the theoretical models was made by means of a Levenberg-Marquardt optimization routine implemented in Mathcad ${ }^{\circledR}$ software, version 14 (PTC).

\section{Results and discussion}

Figure 1 shows a representative voltammetric cycle of $\mathrm{PB}$ film in a $0.5 \mathrm{M} \mathrm{NH}_{4} \mathrm{Cl}$ acid solution. In the case of $\mathrm{NH}_{4}^{+}$cations, voltammograms show two well-defined voltammetric peaks, but the anodic peak is relatively wide and small. In Figure 1, the anodic peak intensity and the width of the anodic peak at half height are around $0.35 \mathrm{~mA} \mathrm{~cm}{ }^{-2}$ and $275 \mathrm{mV}$, 
respectively. On the contrary, the cathodic peak shows values around $-0.5 \mathrm{~mA} \mathrm{~cm}{ }^{-2}$ and 180 $\mathrm{mV}$. The electrochemical reduction of PB to the ES under these experimental conditions can be described by the following simplified reaction scheme:

$$
\mathrm{NH}_{4} \mathrm{Fe}^{\mathrm{III}}\left[\mathrm{Fe}^{\mathrm{II}}(\mathrm{CN})_{6}\right]+\mathrm{e}^{-}+\mathrm{NH}_{4}^{+} \underset{k_{\mathrm{i}}^{\prime}}{\stackrel{k_{\mathrm{i}}}{\rightarrow}}\left(\mathrm{NH}_{4}\right)_{2} \mathrm{Fe}^{\mathrm{II}}\left[\mathrm{Fe}^{\mathrm{II}}(\mathrm{CN})_{6}\right]
$$

Previous spectroelectrochemical studies of $\mathrm{PB}$ films in $\mathrm{KCl}$ solutions have shown that changes of absorbance at wavelengths close to $690 \mathrm{~nm}$ could be associated to an electronic transfer between low spin $\mathrm{Fe}^{\mathrm{II}}\left(\mathrm{Fe}_{\mathrm{ls}}^{\mathrm{II}}\right)$ and high spin iron sites $\left(\mathrm{Fe}_{\mathrm{hs}}^{\mathrm{III}}\right)$ in the $\mathrm{Fe}_{\mathrm{ls}}^{\mathrm{II}}-\mathrm{CN}-\mathrm{Fe}_{\mathrm{hs}}^{\mathrm{III}}$ structure [16]. The redox processes associated to the $\mathrm{Fe}_{\mathrm{hs}}^{\mathrm{III}}$ is the most of electrochemical response observed in the $\mathrm{PB} \rightleftarrows \mathrm{ES}$ system. This was attributed to the size changes in channel radii of the Prussian blue which inhibits the $\mathrm{Fe}_{\mathrm{ls}}^{\mathrm{II}}$ system[35, 36]. However, electrogravimetric and spectroelectrochemical studies have shown that the voltammetric peaks in $P B$ films is a combination of three different electrochemical processes $[8,16,17]$. Thus, changes around 900 $\mathrm{nm}$ have been associated to at least three different processes [17]: i) a forbidden transition also associated to the transition at $690 \mathrm{~nm}$, ii) an electrochemical process of $\mathrm{Fe}^{\mathrm{III}}$ sites near the ferrocyanide vacancies in the PB structure and iii) an electrochemical processes associated to the structure $\mathrm{Fe}_{\mathrm{ls}}^{\mathrm{III}}-\mathrm{CN}-\mathrm{Fe}_{\mathrm{hs}}^{\mathrm{II}}$ (trapping) in the $\mathrm{PB}$ structure. These electrochemical processes take place by the participation of different counterions in $\mathrm{KCl}$ solutions [7, 8].

Figure 2 shows the complete electrochromic information of PB in the visible and near infrared region expressed as absorbance time-derivative, $\mathrm{d} A^{\lambda} / \mathrm{d} t$, between $450 \mathrm{~nm}$ and $950 \mathrm{~nm}$ during a voltammetric experiment where the $\mathrm{PB} \rightleftarrows \mathrm{ES}$ process occurs in a $\mathrm{NH}_{4} \mathrm{Cl}$ solution. The solid and dotted lines of the contour plot represent positive and negative regions of $\mathrm{d} A^{\lambda} / \mathrm{d} t$, respectively. The results are qualitatively similar to that obtained in the literature for PB films in $\mathrm{KCl}$ solutions where a decrease of absorbance is observed during the reduction of PB and an increase of absorbance takes place during the oxidation to ES [14, 37]. As it can be seen, the maximum positive and negative changes of absorbance close to $690 \mathrm{~nm}$ agree with the voltammetric peaks. However, the maximum positive and negative $\mathrm{d} A^{\lambda} / \mathrm{d} t$ close to $900 \mathrm{~nm}$ are slightly displaced due the overlapped processes: the maximum negative is reached after the cathodic peak and the maximum positive is before the anodic peak considering the potential scan direction. Therefore, $690 \mathrm{~nm}$ and $900 \mathrm{~nm}$ are also characteristic wavelengths in $\mathrm{NH}_{4} \mathrm{Cl}$ solutions. 
Figure 3 shows an example of EIS, MIS and CIS at both characteristic wavelengths and at a potential of $0.2 \mathrm{~V}$. Electrochemical impedance spectra as $\Delta q / \Delta E$ appears as two loops in the first quadrant indicating that at least two ions are involved in the electrochemical process(Figure 3a). Therefore, the electrochemical reactions of $\mathrm{PB}$ films in $\mathrm{NH}_{4} \mathrm{Cl}$ solution prove more complicated than the simplistic reaction showed in equation (3). At this potential and as it occurs in $\mathrm{KCl}$ solutions, a major response as one loop on the third quadrant for the mass impedance data proving the main participation of cations as counterions is observed (Figure 3b). However, in this case a low frequencies contribution on in the fourth quadrant is also shown. Color impedance loops appear in the first quadrant at $690 \mathrm{~nm}$ (Figure 3c) and at $900 \mathrm{~nm}$ (Figure 3d) since the absorptivity for the oxidized form of the films proves to be larger. However, compared with EIS, MIS and CIS in $\mathrm{KCl}$ solutions at that potential the first difference is that these responses appear as two loops and they are flattened [16]. This non-ideal shape of these loops may be attributed to different reasons. One of the possibilities is that these flattened loops are the result of the overlapping of more than one ideal loop. There are other possible reasons such as a non-uniform electrode surface causing a potential distribution on the electrode surface. Another unexplored possibility is the non-reversible character of the electrochemical processes around the $\mathrm{PB} \rightleftarrows \mathrm{ES}$ system in solutions containing $\mathrm{NH}_{4}^{+}$cations. If the voltammogram corresponding this redox process in a $\mathrm{NH}_{4} \mathrm{Cl}$ solution in Figure 1 was examined carefully, one can observe that the redox peaks appear less symmetric than that in the case of $\mathrm{KCl}$ solutions. $\mathrm{NH}_{4}^{+}$cations could be easier inserted during the reduction reaction than expulsed during the oxidation reaction.

The interpretation of experimental data provided by impedance techniques requires an examination of a kinetic model. In our case, an insertion model is used where the insertion/expulsion of species into the film controls the overall rate of the electrochemical process. The rate of transport related to the counterions, through the film, is characterized by the time constant parameter $\tau[9,30,38]$. The change of flux of the specie i through the conducting film/solution interface caused by the sinusoidal potential perturbation can be written as $[26,27]$ :

$$
\Delta J_{\mathrm{i}}=-j \omega d \Delta C_{\mathrm{i}}=K_{\mathrm{i}} \Delta C_{\mathrm{i}}+G_{\mathrm{i}} \Delta E
$$

Therefore, the parameters $K_{\mathrm{i}}$ and $G_{\mathrm{i}}$ can be expressed from the partial derivative of the flux of exchanged species by: 


$$
\begin{gathered}
K_{\mathrm{i}}=\left(\frac{\partial J_{\mathrm{i}}}{\partial C_{\mathrm{i}}}\right)_{E}=k_{\mathrm{i}}+k_{\mathrm{i}}^{\prime} C_{\mathrm{i}}^{\text {sol }} \\
G_{\mathrm{i}}=\left(\frac{\partial J_{\mathrm{i}}}{\partial E}\right)_{C_{\mathrm{i}}}=-b_{\mathrm{i}} k_{\mathrm{i}}\left(C_{\mathrm{i}}-C_{\mathrm{i}}^{\min }\right)+b_{\mathrm{i}}^{\prime} k_{\mathrm{i}}^{\prime}\left(C_{\mathrm{i}}^{\mathrm{max}}-C_{\mathrm{i}}\right) C_{\mathrm{i}}^{\text {sol }}
\end{gathered}
$$

where $C_{\mathrm{i}}^{\text {sol }}$ corresponds to the concentration of the specie $\mathrm{i}$ in the solution, $C_{\mathrm{i}}^{\max }$ and $C_{\mathrm{i}}^{\min }$ the maximum and minimum concentration of sites for insertion in the electroactive polymer, respectively. The $k_{\mathrm{i}}$ and $k_{\mathrm{i}}{ }^{\prime}$ parameters are the kinetics constants for direct and reverse insertion reaction, equation (3). These constants have a Butler-Volmer dependence on the potential:

$$
k_{\mathrm{i}}=k_{\mathrm{i}, 0} \exp \left[b_{\mathrm{i}}\left(E-E_{\mathrm{i}}^{0^{\prime}}\right)\right] \quad k_{\mathrm{i}}^{\prime}=k_{\mathrm{i}, 0}^{\prime} \exp \left[b_{\mathrm{i}}^{\prime}\left(E-E_{\mathrm{i}}^{0^{0^{\prime}}}\right)\right]
$$

where parameters $b_{\mathrm{i}}$ and $b_{\mathrm{i}}^{\prime}$ are related with the number of electrons participating during the redox process and with the transfer coefficient $\beta$ :

$$
b_{\mathrm{i}}=-\beta \frac{n_{\mathrm{i}} F}{R T} \quad b_{\mathrm{i}}^{\prime}=(1-\beta) \frac{n_{\mathrm{i}} F}{R T}
$$

As a first approach, we can consider that $\beta=0.5$ and then, $b_{\mathrm{i}}=-b_{\mathrm{i}}^{\prime}$. In this case, the dependence of $\log G_{\mathrm{i}}$ on the applied potential proves to be symmetrical with respect to the formal potential $E_{\mathrm{i}}^{0^{\prime}}$. At steady state conditions, the dependence of $G_{\mathrm{i}}$ parameters on the applied potential can be expressed by [39]:

$$
G_{\mathrm{i}}=\frac{G_{\mathrm{i}}^{\max }}{\cosh \left[\frac{B_{\mathrm{i}}\left(E-E_{\mathrm{i}}^{0 \prime}\right)}{2}\right]}
$$

where $B_{\mathrm{i}} / 2=19.5 \mathrm{~V}^{-1}$ for a reversible process at $298 \mathrm{~K}$ considering equation $(8) . G_{\mathrm{i}}^{\max }$ represents the maximum value for this parameter and corresponds to the potential $E=E_{\mathrm{i}}^{0^{\prime}}$.

Accordingly, the insertion law for each participating species can be mathematically expressed by this model as:

$$
\frac{\mathrm{d} C_{i}}{\mathrm{~d} E}=\frac{G_{\mathrm{i}}}{K_{\mathrm{i}}}=\frac{B_{\mathrm{i}}}{4} \frac{C_{\mathrm{i}}^{\max }}{\cosh ^{2}\left[\frac{B_{\mathrm{i}}\left(E-E_{\mathrm{i}}^{0^{\prime}}\right)}{2}\right]}
$$

Therefore, the parameters $B_{\mathrm{i}}, E_{\mathrm{i}}^{0^{\prime}}$ and $C_{\mathrm{i}}^{\max }$ can be estimated by the appropriate fitting of the dependence of these parameters on the applied potential. Moreover, the parameter $d$ represents the film thickness and in most cases, it is often difficult to obtain a good estimation. Therefore, we can include the thickness in the $K_{\mathrm{i}}$ parameter as $K_{\mathrm{di}}=K_{\mathrm{i}} / d$. Consequently, $G_{\mathrm{i}} / K_{\mathrm{di}}$ is the insertion law in terms of surface concentration, $\mathrm{d} \Gamma_{\mathrm{i}} / \mathrm{d} E$ : 


$$
\frac{\mathrm{d} \Gamma_{\mathrm{i}}}{\mathrm{d} E}=\frac{G_{\mathrm{i}}}{K_{\mathrm{i}} / d}=\frac{G_{\mathrm{i}}}{K_{\mathrm{di}}}=\frac{B_{\mathrm{i}}}{4} \frac{\Gamma_{\mathrm{i}}^{\max }}{\cosh ^{2}\left[\frac{B_{\mathrm{i}}\left(E-E_{\mathrm{i}}^{0^{\prime}}\right)}{2}\right]}
$$

where $\Gamma_{\mathrm{i}}^{\max }$ is the maximum surface concentration of sites for insertion in the electroactive polymer.

On the basis of this model, the faradaic impedance if we consider two different counterions can be written as $[17,30]$ :

$$
Z_{\mathrm{F}}=\frac{1}{1+K_{\mathrm{d} 1} \frac{\operatorname{coth}\left(\sqrt{j \omega \tau_{1}}\right)}{\sqrt{j \omega / \tau_{1}}}+\frac{F G_{2}}{1+K_{\mathrm{d} 2} \frac{\operatorname{coth}\left(\sqrt{j \omega \tau_{2}}\right)}{\sqrt{j \omega / \tau_{2}}}}}
$$

This model has been previously tested in PB film immersed in $\mathrm{KCl}$ solutions and provided coherent results $[16,17]$.

Equation (12) can be rewritten as a charge/potential transfer function, $\Delta q / \Delta E(\omega)$ :

$$
\frac{\Delta q}{\Delta E}(\omega)=\frac{1}{j \omega}\left(\frac{F G_{1}}{1+K_{\mathrm{d} 1} \frac{\operatorname{coth}\left(\sqrt{j \omega \tau_{1}}\right)}{\sqrt{j \omega / \tau_{1}}}}+\frac{F G_{2}}{1+K_{\mathrm{d} 2} \frac{\operatorname{coth}\left(\sqrt{j \omega \tau_{2}}\right)}{\sqrt{j \omega / \tau_{2}}}}\right)
$$

This expression is also valid for mass impedance and color impedance at a given wavelength by replacing the Faraday constant by $\delta_{M_{\mathrm{i}}} M_{\mathrm{i}}$ for the mass impedance and $\delta_{\varepsilon_{\mathrm{i}}} \varepsilon_{\mathrm{i}}$ for the color impedance at a given wavelength obtaining the impedance transfer functions for MIS $(\Delta m / \Delta E(\omega))$, and for CIS $\left(\Delta A^{\lambda} / \Delta E(\omega)\right)$, respectively:

$$
\begin{aligned}
& \frac{\Delta m}{\Delta E}(\omega)=\frac{1}{j \omega}\left(\frac{\delta_{M_{1}} M_{1} G_{1}}{1+K_{\mathrm{d} 1} \frac{\operatorname{coth}\left(\sqrt{j \omega \tau_{1}}\right)}{\sqrt{j \omega / \tau_{1}}}}+\frac{\delta_{M_{2}} M_{2} G_{2}}{1+K_{\mathrm{d} 2} \frac{\operatorname{coth}\left(\sqrt{j \omega \tau_{2}}\right)}{\sqrt{j \omega / \tau_{2}}}}\right) \\
& \frac{\Delta A^{\lambda}}{\Delta E}(\omega)=\frac{1}{j \omega}\left(\frac{\delta_{\varepsilon_{1}} \varepsilon_{1} G_{1}}{1+K_{\mathrm{d} 1} \frac{\operatorname{coth}\left(\sqrt{j \omega \tau_{1}}\right)}{\sqrt{j \omega / \tau_{1}}}}+\frac{\delta_{\varepsilon_{2}} \varepsilon_{2} G_{2}}{1+K_{\mathrm{d} 2} \frac{\operatorname{coth}\left(\sqrt{j \omega \tau_{2}}\right)}{\sqrt{j \omega / \tau_{2}}}}\right)
\end{aligned}
$$

where $M_{\mathrm{i}}$ represents the molar mass of the inserted or expelled species and $\varepsilon_{\mathrm{i}}$ the electrochromic efficiency at a given wavelength $\lambda$. The parameters $\delta_{M_{\mathrm{i}}}$ and $\delta_{\varepsilon_{\mathrm{i}}}$ can only be 1 or -1 . If the mass 
or the absorbance increases with the potential, it is positive and this value is negative if the opposite occurs.

It is our interest to obtain quantitative information about these electrochemical processes from these experiments. For that purpose, we can fit experimental impedance data to the equations (13)-(15) corresponding to the theoretical insertion model for two counterions species. As an example, lines in Figure 3 show the fittings to the experimental data for the EIS, MIS and CIS for both wavelengths (690 nm and $900 \mathrm{~nm}$ ) at $0.2 \mathrm{~V}$. It should be noted that the shape of the loops is not perfectly reproduced. The experimental loops appear more flattened than the fitted-simulated loops. Therefore, we need at least two loops, but that is not the only reason of the non-ideal shape of loops and it will be discussed in the following.

In the case of MIS at some potentials, the low frequencies loop appears on the fourth quadrant and it means that the $\delta_{M}$ changes from negative to positive values. In this case, a possible explanation is that the charge balance takes place by the participation of an anion or also that the exchange of cations is accompanied by the opposite flux of the solvent.

A deeper analysis is possible by examining the dependence on the stabilization potential of the parameters obtained from the fitting of experimental data to the model described by equations (13)-(15) for two processes. Impedance measurements allow the responses due to the faster and slower processes to be separated by changing the frequency of the potential perturbation. Therefore, the responses will be seen as a slow process and a fast process. This difference is correlated to the time constant $\tau_{\mathrm{i}}$ obtained for each one of the processes in the four impedance functions analyzed. Figure 4 shows the variation of the time constant for the faster (a) and for the slower (b) processes. The fast process in all cases shows minimum time constants at potentials about $0.2 \mathrm{~V}$, while for the slower one, the minimum is at potentials about $0.15 \mathrm{~V}$. At these potentials, the faradaic processes occur, thus the changes of mass and color are clearly related with faradaic processes in the PB films. However, for the faster process and at $900 \mathrm{~nm}$ a minimum of the time constant is obtained at potentials near $0.35 \mathrm{~V}$ (Figure 4a). At these potentials and in $\mathrm{KCl}$ solutions, it has also been detected a change of absorbance at $900 \mathrm{~nm}$ associated to the participation of $\mathrm{H}^{+}$as counterions [10]. Therefore, this could be extrapolated to these experimental conditions.

The dependence of $\mathrm{d} \Gamma_{\mathrm{i}} / \mathrm{d} E$ on the applied potential is plotted in Figure 5 for the fast (a) and for the slow (b) processes. This variable is a measure of the contribution of each process to the overall response. For the fast process, we obtain maximum values for this parameter at 
different potentials. A possible explanation is that the overall response is not only due to a single process. It can be better understood if the response associated to the CIS at 690 and at $900 \mathrm{~nm}$ in Figure 5a is carefully examined. Maximum values are obtained at different potentials. At potentials in the range $0-0.15 \mathrm{~V}$ there is no response at $690 \mathrm{~nm}$, but a clear contribution appears at $900 \mathrm{~nm}$. EIS, MIS and CIS at $900 \mathrm{~nm}$ maximum are obtained at larger potentials than that of the CIS at $690 \mathrm{~nm}$ measurements. This can be due to the fact that at these potentials there exists electrochemical processes associated to the ferrocyanide vacancies where the $\mathrm{H}_{3} \mathrm{O}^{+}$has been detected as a counterion [17]. This process does not involve color changes at $690 \mathrm{~nm}$, and thus the contribution at this wavelength clearly decreases. Nevertheless, the mass does not change significantly between $\mathrm{NH}_{4}^{+}$and $\mathrm{H}_{3} \mathrm{O}^{+}$.

There is also an interesting MIS behavior for the slow process at potentials in the range 0.15-0.2 V in Figure 5b, where the low frequencies loop appears on the fourth quadrant. This may be explained by a second contribution on the opposite flux direction of that of the cations. This can be due to an anion participation as counterion and/or the flux of water molecules due to the exclusion effect associated to the insertion-expulsion of $\mathrm{NH}_{4}^{+}$cation. From these results, it is not possible to discern between these two possibilities. However, studies of the role of inner water molecules on the electrochemistry of PB films have shown that an exchange of water molecules takes place at these potentials [8].

We can estimate the molar mass of participating species from the values of $M_{\mathrm{i}} G_{\mathrm{i}} / K_{\mathrm{di}}$ obtained from the low frequencies limit of $\Delta m / \Delta E$, and the values of $F G_{\mathrm{i}} / K_{\mathrm{di}}$ obtained from the low frequencies limit of $\Delta q / \Delta E$ for both processes. Similarly, the electrochromic efficiency $\varepsilon_{i}$ associated to each one of the electroactive processes are obtained by comparing $\Delta q / \Delta E$ and $\Delta A^{\lambda} / \Delta E$.

$$
\begin{gathered}
F \frac{\Delta m / \Delta E}{\Delta q / \Delta E}=F \frac{\Delta m}{\Delta q}=\frac{M}{Z} \\
F \frac{\Delta A^{\lambda} / \Delta E}{\Delta q / \Delta E}=F \frac{\Delta A^{\lambda}}{\Delta q}=\frac{\varepsilon}{Z}
\end{gathered}
$$

where $z$ is the number of electrons involved per active center in the electrochemical process.

In the potential ranged from 0.1 to $0.2 \mathrm{~V}$ the slowest process shows a very small associated molar mass of participating species (about $1 \mathrm{~g} \mathrm{~mol}^{-1}$ ) that can be attributed to an exchange of other species - probably water molecules - in the opposite direction of the 
ammonium flux $[8,40]$. It is better observed in Figure 6 where the crossed impedance functions $F \Delta m / \Delta q$ at $0.15 \mathrm{~V}$ decrease from high to low frequencies, which is in good agreement with the hypothesis of a slow process in the opposite sense. Figure $3 \mathrm{~b}$ shows also that the fitting of MIS experimental data to the proposed model needs a second loop on the fourth quadrant.

At other potentials, the molar mass associated to this process is close to the expected molar mass for the ammonium cation $\left(18 \mathrm{~g} \mathrm{~mol}^{-1}\right)$. For the fast process, a molar mass about 18 $\mathrm{g} \mathrm{mol}^{-1}$ is obtained in the full range of potentials. If compared with the case of PB films in $\mathrm{KCl}$ solutions, it should be noted here that in $\mathrm{NH}_{4} \mathrm{Cl}$ solutions we cannot discern between the hydrated proton and the salt cation since the molar masses are very similar. In spite of this, the participation of both species is expected by analogy with results of $\mathrm{PB}$ films in $\mathrm{KCl}$ solutions $[16,17]$.

$F \Delta A^{\lambda} / \Delta q(\omega)$ values at $690 \mathrm{~nm}$ and $900 \mathrm{~nm}$ are shown in Figure $7 \mathrm{a}$ and Figure $7 \mathrm{~b}$, respectively. The electrochromic efficiency at $900 \mathrm{~nm}$ estimated as $F \Delta A^{900} / \Delta q(\omega)$ decreases with the applied potential obtaining the maximum value at potentials near $0.1 \mathrm{~V}$, far from the redox potential of the $\mathrm{PB} \rightleftarrows \mathrm{ES}$ process. This indicates that the changes of absorbance at this wavelength are not associated to the main electrochemical process. This is not the case for the process at $690 \mathrm{~nm}$, where the maximum of electrochromic efficiency is reached at potentials near the redox potential of the main process $(0.25 \mathrm{~V})$. At potentials slightly higher than the redox potential, the electrochromic efficiency quickly decreases at this wavelength and no color change at $690 \mathrm{~nm}$ is observed.

\section{Conclusion}

Acquisition of three impedances simultaneously allowed the valuable information on the electrochemical behavior of $\mathrm{PB}$ films in $\mathrm{NH}_{4} \mathrm{Cl}$ solutions to be obtained. The impedance responses appear as double loops and more flattened than that in $\mathrm{KCl}$ solutions. The voltammograms in $\mathrm{NH}_{4} \mathrm{Cl}$ solutions clearly show a smaller and a wider anodic peak. This behavior could be the reason of the non-ideal loops. Ammonium cations have shown a large affinity for PB films [19] which means that there is no extra difficulty for these cations to be inserted in the film. However, the expulsion can be more difficult. The size of $\mathrm{NH}_{4}^{+}$and $\mathrm{K}^{+}$ cations is not very different, but the chemical affinity of iron sites for ammonium or potassium ions can be very different. This causes an apparent non-reversibility of the redox behavior and results in the non-ideal loops on the impedance plots. 
In spite of the fact that two electrochemical processes (equations (13)-(15)) were used to better fit the experimental data to our theoretical model, there is a point to be clarified here. The electrochemical response of PB films in $\mathrm{KCl}$ solutions has been described as the overlap of at least three different processes. Working at a fixed potential can mean that one of these three processes is far from taking place, and thus this contribution can be neglected. These responses have been separated as a fast and a slow process; faster process is generally due to the main redox process, but the slower process is probably different when applied potential changes. Most likely for this reason, we obtain two peaks for the slower process.

If these results are compared with those obtained for the PB films in $\mathrm{KCl}$ solutions, we can also consider three different processes. The main process is associated to the backbone structure of the PB films, which is related to the exchange of ammonium cations and to the changes of absorbance at $690 \mathrm{~nm}$. The second process occurs at slightly larger potentials and is associated to the exchange of $\mathrm{H}_{3} \mathrm{O}^{+}$or $\mathrm{NH}_{4}^{+}$cations (it is not possible to discern between these possibilities since both cations have a similar molar mass). At these potentials, there is no color change at $690 \mathrm{~nm}$ and a slight change of color at $900 \mathrm{~nm}$. This process has been associated to the electrochemistry of the ferrocyanide vacancies. The third process is associated to an electron transition in trapped sites $\mathrm{Fe}_{\mathrm{ls}}^{\mathrm{III}}-\mathrm{CN}-\mathrm{Fe}_{\mathrm{hs}}^{\mathrm{II}}$. This process is well localized at potentials near $0.1 \mathrm{~V}$ where the maximum of electrochromic efficiency at $900 \mathrm{~nm}$ is reached.

The $F \Delta m / \Delta q$ function shows clearly that at low frequencies an opposite flux of solvent takes place at potentials between 0.15 and $0.20 \mathrm{~V}$. This explains the appearance of a second loop on the fourth quadrant in the mass impedance measurement.

\section{Acknowledgments}

Part of this work was supported by FEDER-CICyT project CTQ2011-28973/BQU.

\section{References}

1. Neff VD (1978) Electrochemical Oxidation and Reduction of Thin Films of Prussian Blue. J Electrochem Soc 125:886-887.

2. Itaya K, Ataka T, Toshima S (1982) Spectroelectrochemistry and electrochemical preparation method of Prussian blue modified electrodes. J Am Chem Soc 104:47674772 .

3. Karyakin AA (2001) Prussian Blue and its analogues: Electrochemistry and analytical applications. Electroanalysis 13:813-819.

4. Neff V (1985) Some Performance-Characteristics of a Prussian Blue Battery. J Electrochem Soc 132:1382-1384. 
5. Mortimer RJ, Rosseinsky DR (1984) Iron Hexacyanoferrate Films - Spectroelectrochemical Distinction and Electrodeposition Sequence of Soluble (K+-Containing) and Insoluble (K+-Free) Prussian Blue, and Composition Changes in Polyelectrochromic Switching. J Chem Soc-Dalton Trans 2059-2061.

6. Mortimer RJ, Rosseinsky DR (1983) Electrochemical Polychromicity in Iron Hexacyanoferrate Films, and a New Film Form of Ferric Ferricyanide. J Electroanal Chem 151:133-147.

7. Feldman B, Melroy O (1987) Ion Flux During Electrochemical Charging of Prussian Blue Films. J Electroanal Chem 234:213-227.

8. Garcia-Jareño J, Sanmatias A, Navarro-Laboulais J, Vicente F (1998) The role of potassium and hydrogen ions in the Prussian Blue reversible arrow Everitt's salt process. Electrochimica Acta 44:395-405.

9. Gabrielli C, García-Jareño JJ, Keddam M, Perrot H, Vicente F (2002) AcElectrogravimetry Study of Electroactive Thin Films. I. Application to Prussian Blue. J Phys Chem B 106:3182-3191.

10. Agrisuelas J, Gabrielli C, Garcia-Jareño JJ, Gimenez-Romero D, Gregori J, Perrot H, Vicente $\mathrm{F}$ (2007) Usefulness of $\mathrm{F}(\mathrm{dm} / \mathrm{dQ})$ function for elucidating the ions role in $\mathrm{PB}$ films. J Electrochem Soc 154:F134-F140.

11. Herren F, Fischer P, Ludi A, Halg W (1980) Neutron-Diffraction Study of Prussian Blue, $\mathrm{Fe} 4[\mathrm{Fe}(\mathrm{CN}) 6] 3 . x H 2 \mathrm{O}$ - Location of Water-Molecules and Long-Range Magnetic Order. Inorg Chem 19:956-959.

12. Roig A, Navarro J, Tamarit R, Vicente F (1993) Stability of Prussian Blue Films on Ito Electrodes - Effect of Different Anions. J Electroanal Chem 360:55-69.

13. Bueno PR, Ferreira FF, Gimenez-Romero D, Setti GO, Faria RC, Gabrielli C, Perrot H, Garcia-Jareno JJ, Vicente F (2008) Synchrotron structural characterization of electrochemically synthesized hexacyanoferrates containing $\mathrm{K}(+)$ : A revisited analysis of electrochemical redox. J Phys Chem C 112:13264-13271.

14. Agrisuelas J, García-Jareño JJ, Moreno-Guerrero C, Roig A, Vicente F (2013) Identification of electroactive sites in Prussian Yellow films. Electrochimica Acta 113:825-833.

15. Roig A, Navarro J, Garcia J, Vicente F (1994) Voltammetric Study on the Stability of Deposited Prussian Blue Films Against Successive Potential Cycling. Electrochimica Acta 39:437-442.

16. Agrisuelas J, Juan Garcia-Jareño J, Gimenez-Romero D, Vicente F (2009) Innovative Combination of Three Alternating Current Relaxation Techniques: Electrical Charge, Mass, and Color Impedance Spectroscopy. Part II: Prussian Blue reversible arrow Everitt's Salt Process. J Phys Chem C 113:8438-8446. 
17. Agrisuelas J, Garcia-Jareño JJ, Vicente F (2012) Identification of Processes Associated with Different Iron Sites in the Prussian Blue Structure by in Situ Electrochemical, Gravimetric, and Spectroscopic Techniques in the dc and ac Regimes. J Phys Chem C 116:1935-1947.

18. Garcia-Jareño JJ, Navarro-Laboulais J, Sanmatias A, Vicente F (1998) The correlation between electrochemical impedance spectra and voltammograms of PB films in aqueous $\mathrm{NH} 4 \mathrm{Cl}$ and $\mathrm{CsCl}$. Electrochimica Acta 43:1045-1052.

19. Garcia-Jareño JJ, Sanmatias A, Benito D, Navarro-Laboulais J, Vicente F (1999) The role of inner counterions within PB films during electrochemical processes. Int J Inorg Mater 1:343-349.

20. Amemiya T, Hashimoto K, Fujishima A (1992) Investigation of Dynamics of Faradaic Processes in Polypyrrole Films by Electrochemical Impedance and Color Admittance Spectroscopies. Denki Kagaku 60:1075-1081.

21. Amemiya T, Hashimoto K, Fujishima A (1993) Dynamics of Faradaic Processes in Polypyrrole Polystyrenesulfonate Composite Films in the Presence and Absence of a Redox Species in Aqueous-Solutions. J Phys Chem 97:4192-4195.

22. Avellaneda CO, Bueno PR, Bulhoes LOS (2001) Synthesis and electrochromic behavior of lithium-doped WO3 films. J Non-Cryst Solids 290:115-121.

23. Garcia-Belmonte G, Bueno PR, Fabregat-Santiago F, Bisquert J (2004) Relaxation processes in the coloration of amorphous WO3 thin films studied by combined impedance and electro-optical measurements. J Appl Phys 96:853-859.

24. Kim JJ, Tryk DA, Amemiya T, Hashimoto K, Fujishima A (1997) Color impedance and electrochemical impedance studies of WO3 thin films: Behavior of thinner films in non-aqueous electrolyte. J Electroanal Chem 433:9-17.

25. Kim JJ, Tryk DA, Amemiya T, Hashimoto K, Fujishima A (1997) Color impedance and electrochemical impedance studies of WO3 thin films: $\mathrm{H}+$ and $\mathrm{Li}+$ transport. J Electroanal Chem 435:31-38.

26. Gabrielli C, Keddam M, Nadi N, Perrot H (1999) ac Electrogravimetry on conducting polymers. Application to polyaniline. Electrochimica Acta 44:2095-2103.

27. Gabrielli C, Keddam M, Perrot H, Pham MC, Torresi R (1999) Separation of ionic and solvent transport during charge compensation processes in electroactive polymers by a.c. electrogravimetry. Electrochimica Acta 44:4217-4225.

28. Gabrielli C, Keddam M, Nadi N, Perrot H (2000) Ions and solvent transport across conducting polymers investigated by ac electrogravimetry. Application to polyaniline. J Electroanal Chem 485:101-113.

29. Yang H, Kwak J (1997) Mass transport investigated with the electrochemical and electrogravimetric impedance techniques .2. Anion and water transport in PMPy and PPy films. J Phys Chem B 101:4656-4661. 
30. García-Jareño JJ, Giménez-Romero D, Vicente F, Gabrielli C, Keddam M, Perrot H (2003) EIS and Ac-Electrogravimetry Study of PB Films in $\mathrm{KCl}, \mathrm{NaCl}$, and $\mathrm{CsCl}$ Aqueous Solutions. J Phys Chem B 107:11321-11330.

31. Gabrielli C, Keddam M, Perrot H, Torresi R (1994) Lithium Insertion in Wo3 Studied by Simultaneous Measurements of Impedance, Electrogravimetric and Electrooptical Transfer-Functions. J Electroanal Chem 378:85-92.

32. Agrisuelas J, Garcia-Jareño JJ, Gimenez-Romero D, Vicente F (2009) Innovative Combination of Three Alternating Current Relaxation Techniques: Electrical Charge, Mass, and Color Impedance Spectroscopy. Part I: The Tool. J Phys Chem C 113:8430-8437.

33. Gabrielli C, Garcia-Jareño JJ, Keddam M, Perrot H, Vicente F (2002) AcElectrogravimetry Study of Electroactive Thin Films. II. Application to Polypyrrole. J Phys Chem B 106:3192-3201.

34. Agrisuelas J, Gabrielli C, Garcia-Jareño JJ, Perrot H, Vicente F (2011) Ionic and Free Solvent Motion in Poly(azure A) Studied by ac-Electrogravimetry. J Phys Chem C 115:11132-11139.

35. Dostal A, Kauschka G, Reddy SJ, Scholz F (1996) Lattice contractions and expansions accompanying the electrochemical conversions of Prussian blue and the reversible and irreversible insertion of rubidium and thallium ions. J Electroanal Chem 406:155-163.

36. Hermes M, Scholz F (1997) The electrochemical determination of ammonium based on the selective inhibition of the low-spin iron(II)/(III) system of Prussian blue. J Solid State Electrochem 1:215-220.

37. Agrisuelas J, Bueno PR, Ferreira FF, Gabrielli C, Garcia-Jareño JJ, Gimenez-Romero D, Perrot H, Vicente F (2009) Electronic Perspective on the Electrochemistry of Prussian Blue Films. J Electrochem Soc 156:P74-P80.

38. Gabrielli C, Garcia-Jareño J, Perrot H (2000) Charge transport in electroactive thin films investigated by ac electrogravimetry. ACH-Models Chem 137:269-297.

39. Agrisuelas J, Gabrielli C, Garcia-Jareño JJ, Gimenez-Romero D, Perrot H, Vicente F (2007) Spectroelectrochemical identification of the active sites for protons and anions insertions into poly-(Azure a) thin polymer films. J Phys Chem C 111:14230-14237.

40. Giménez-Romero D, Bueno PR, García-Jareño JJ, Gabrielli C, Perrot H, Vicente F (2006) Mechanism for Interplay between Electron and Ionic Fluxes in $\mathrm{KhFek}[\mathrm{Fe}(\mathrm{CN}) 6] 1 \cdot \mathrm{mH} 2 \mathrm{O}$ Compounds. J Phys Chem B 110:2715-2722. 
Figures captions

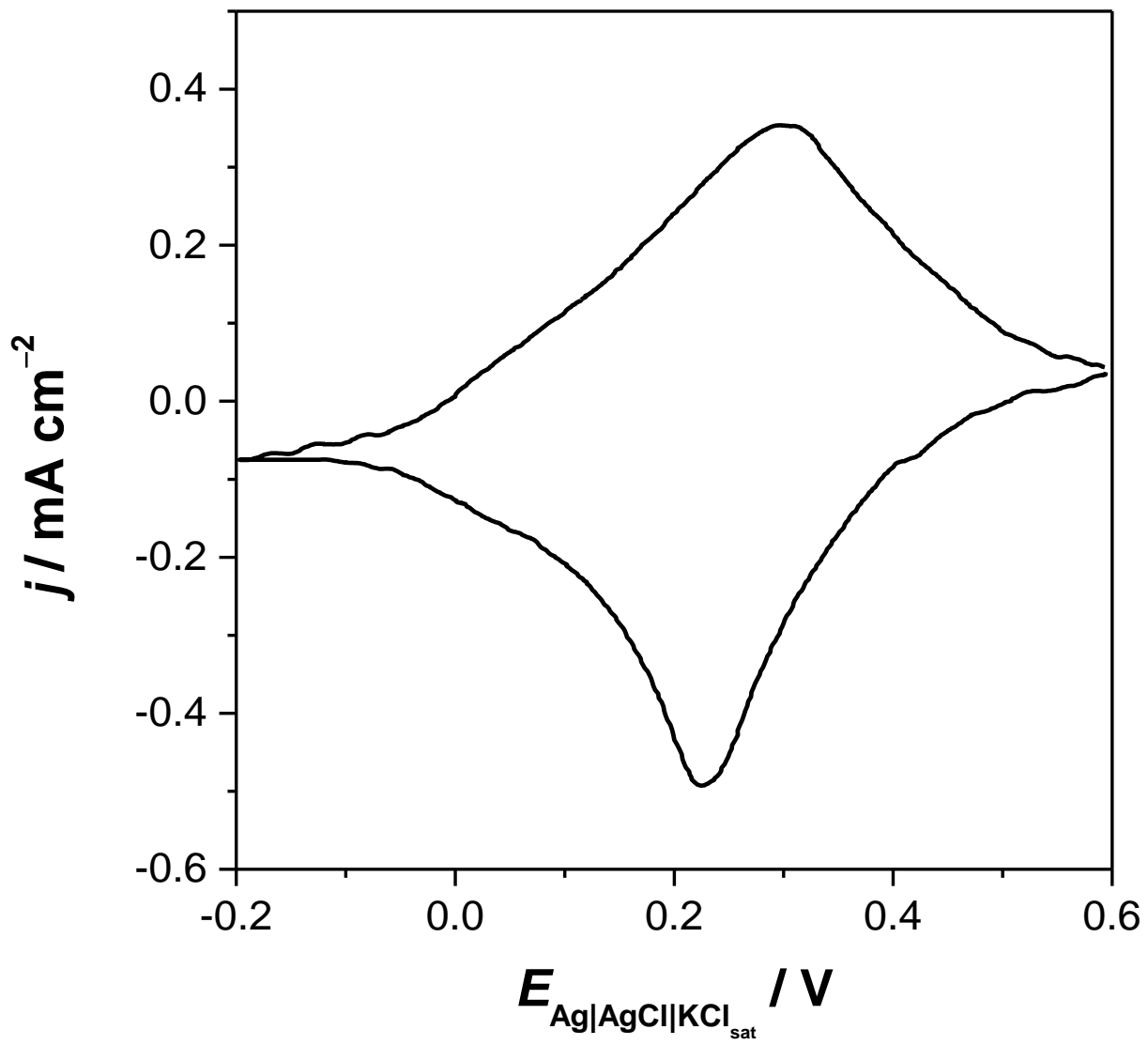

Figure 1. Cyclic voltammogram for a PB film deposited on a gold electrode in a $0.5 \mathrm{M} \mathrm{NH}_{4} \mathrm{Cl}$ acid solution $(\mathrm{pH}=3.0)$ at $20 \mathrm{mV} \mathrm{s}^{-1}$. 


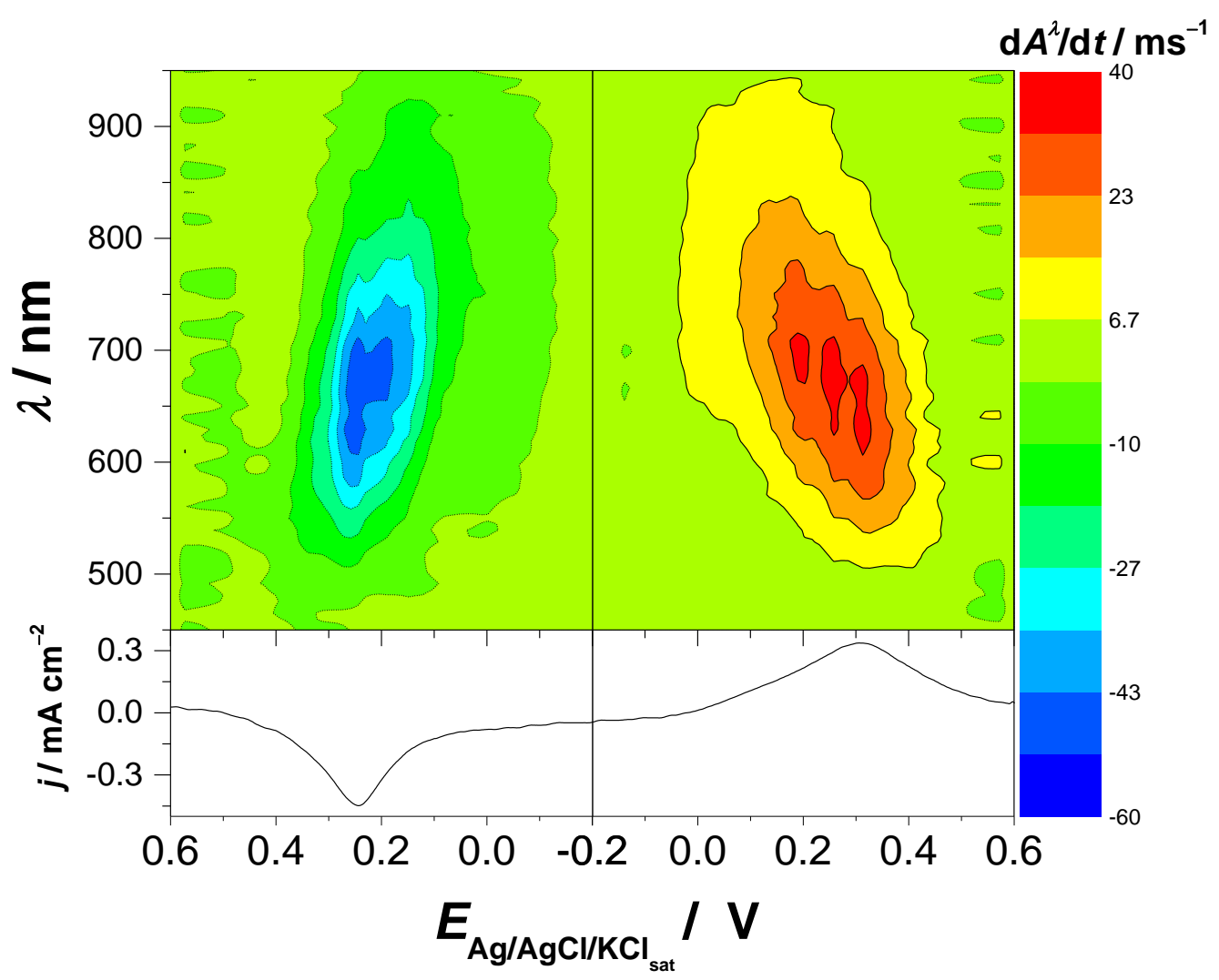

Figure 2. The $\mathrm{d} A^{\lambda} / \mathrm{d} t$ response between $450 \mathrm{~nm}$ and $950 \mathrm{~nm}$ during a cyclic voltammogram for a PB film deposited on a gold electrode in a $0.5 \mathrm{M} \mathrm{NH}_{4} \mathrm{Cl}$ acid solution $(\mathrm{pH}=3.0)$ at $20 \mathrm{mV}$ $\mathrm{s}^{-1}$. The solid and dotted lines of the contour plot represent positive and negative regions of $\mathrm{d} A^{\lambda} / \mathrm{d} t$, respectively. The cyclic voltammogram is represented below the plot for guidance. 


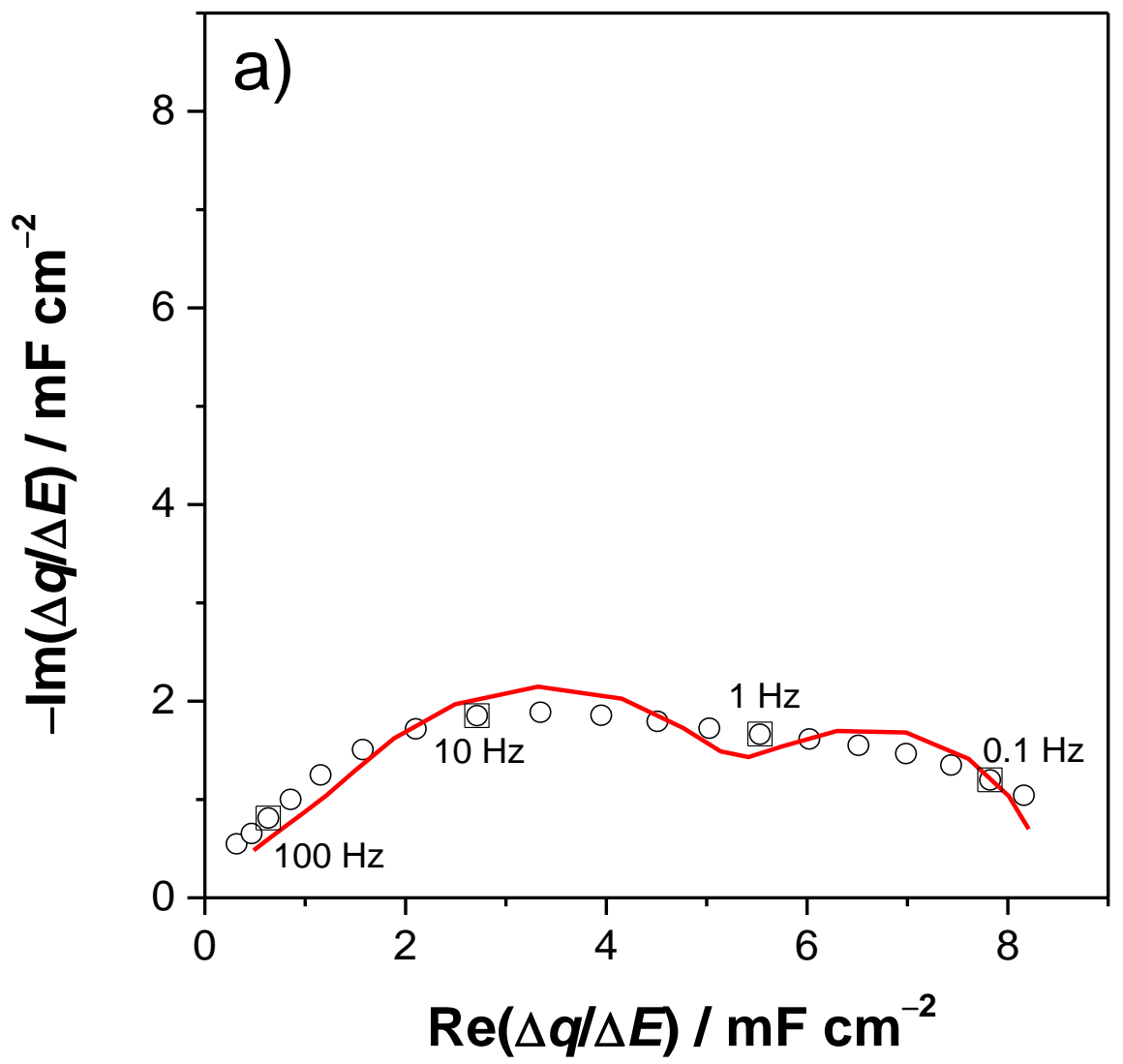




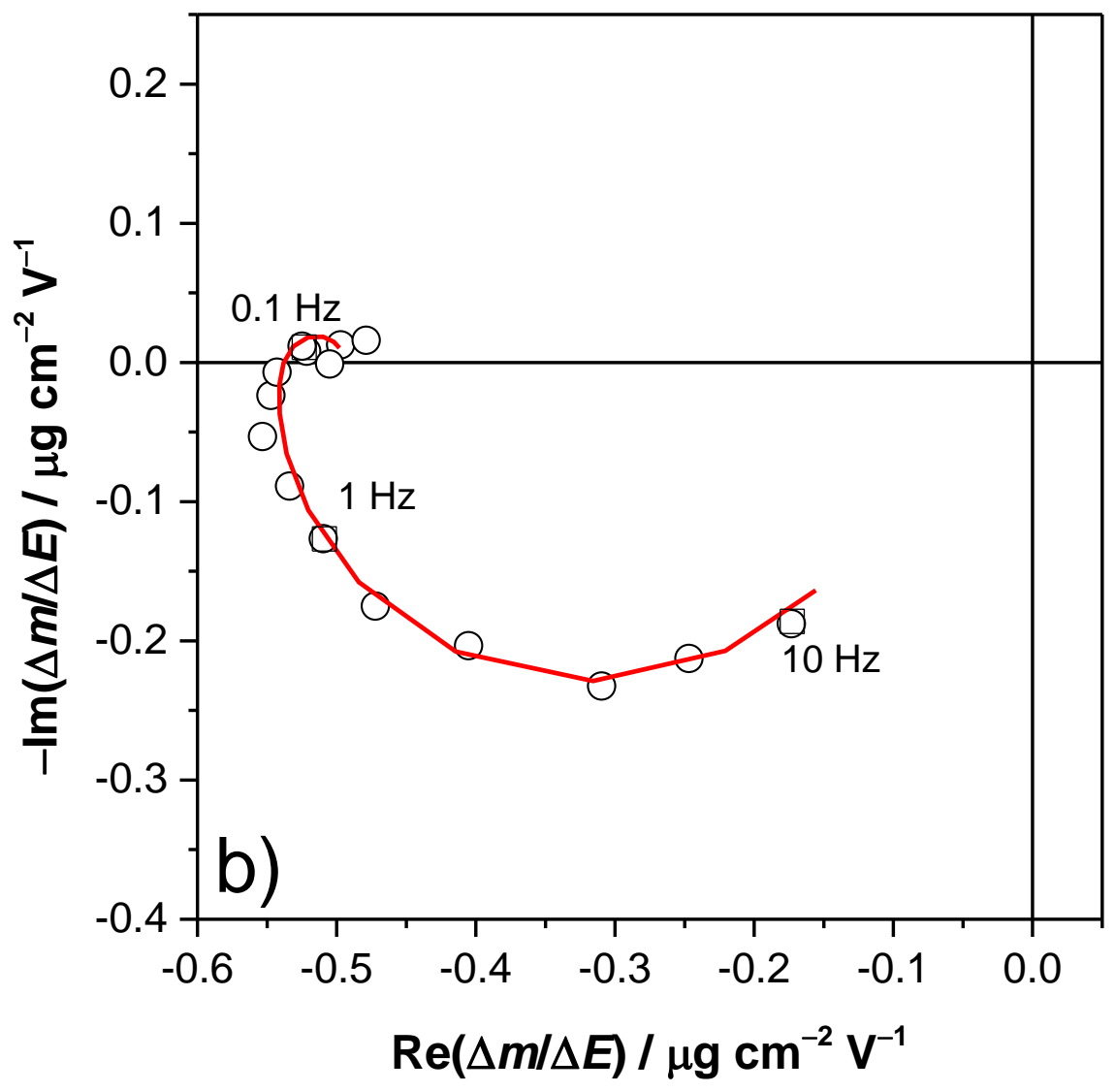




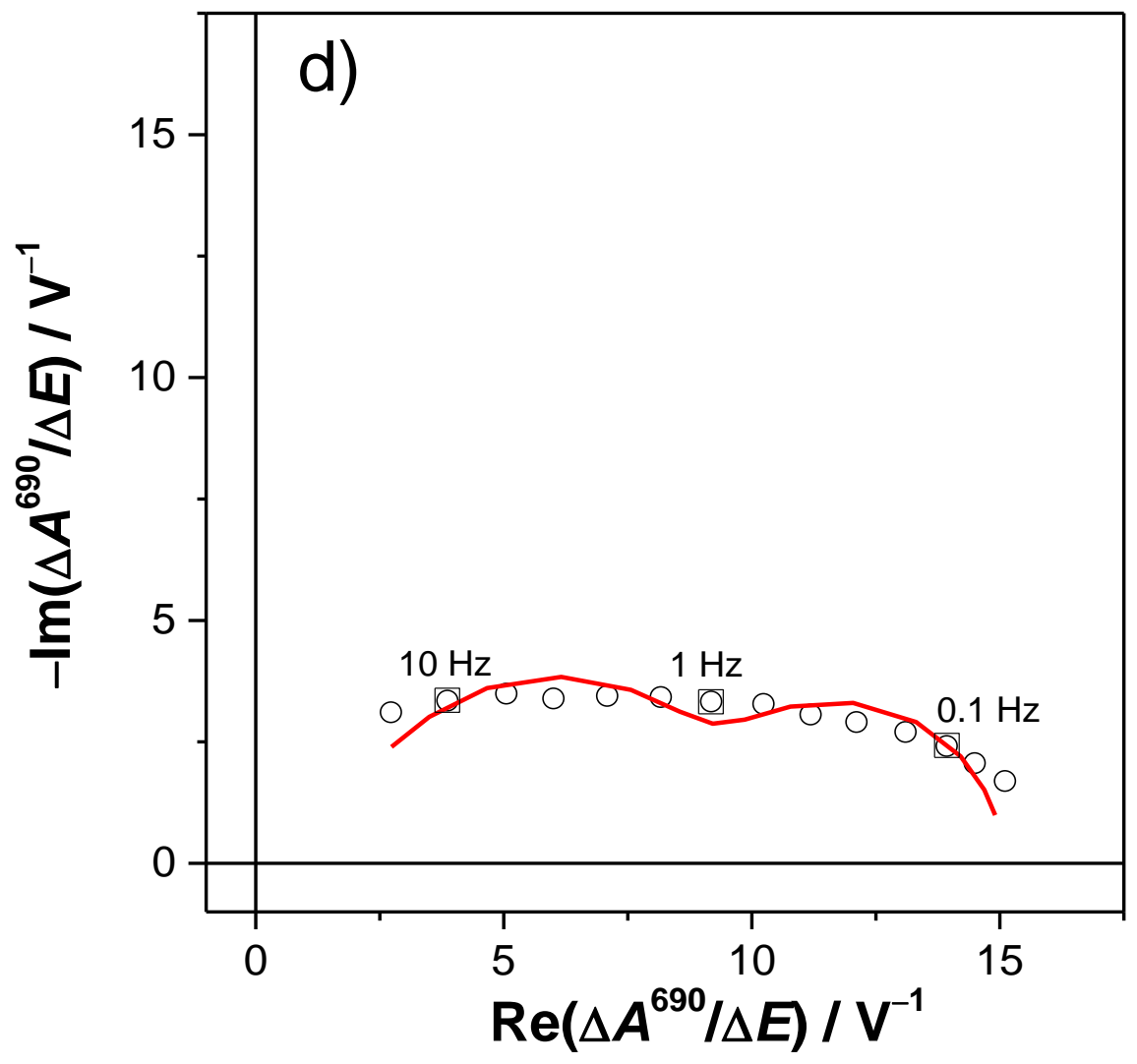




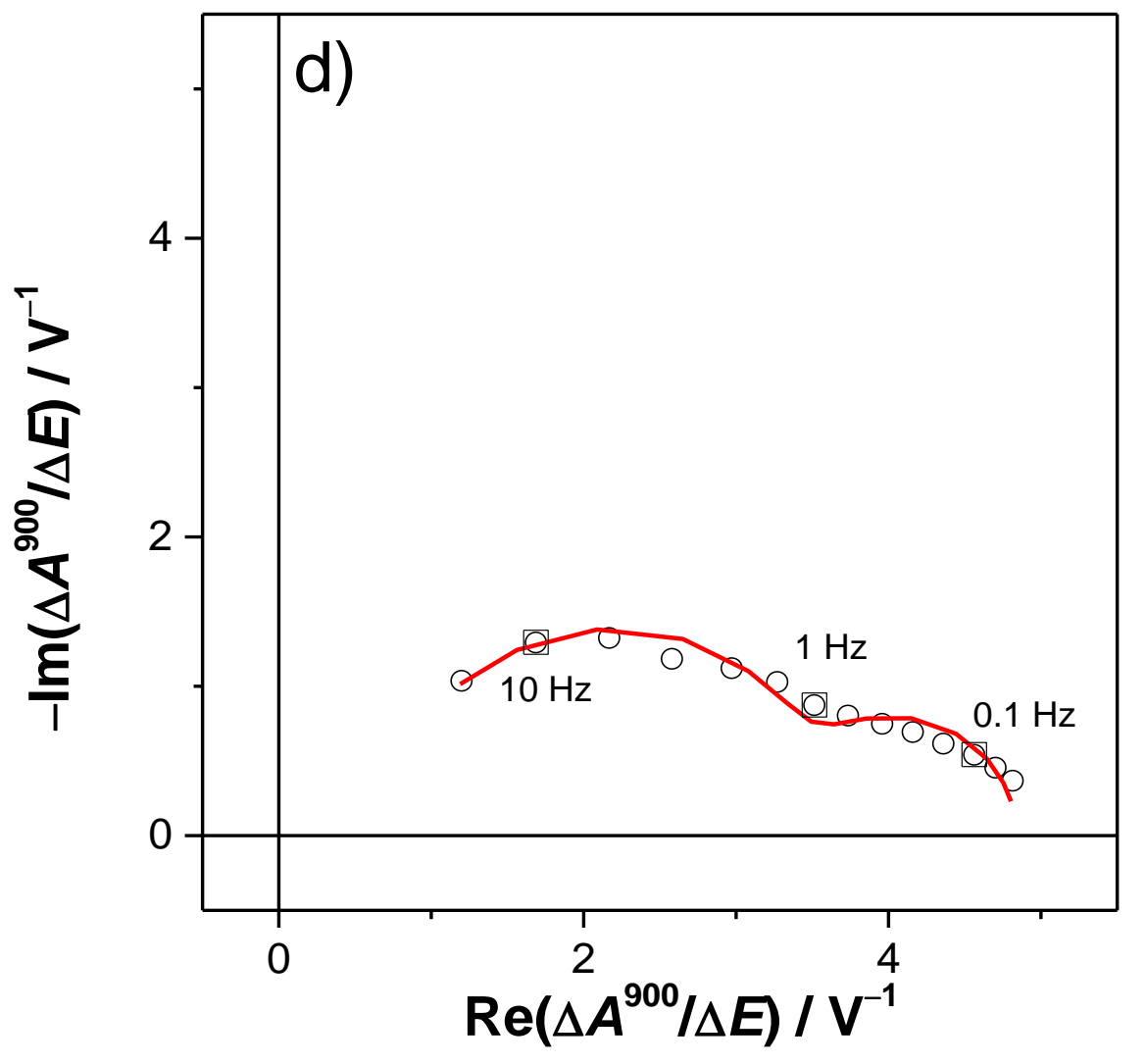

Figure 3. Electrochemical impedance spectroscopy (a), mass impedance (b) and color impedance at $690 \mathrm{~nm}$ (c) and at $900 \mathrm{~nm}$ (d) at $0.2 \mathrm{~V}$ for a PB film deposited on a gold electrode in a $0.5 \mathrm{M} \mathrm{NH}_{4} \mathrm{Cl}$ acid solution ( $\mathrm{pH}=3.0$ ). The lines represent the fittings of impedance spectra with their corresponding theoretical expression (equations (13)-(15)). 


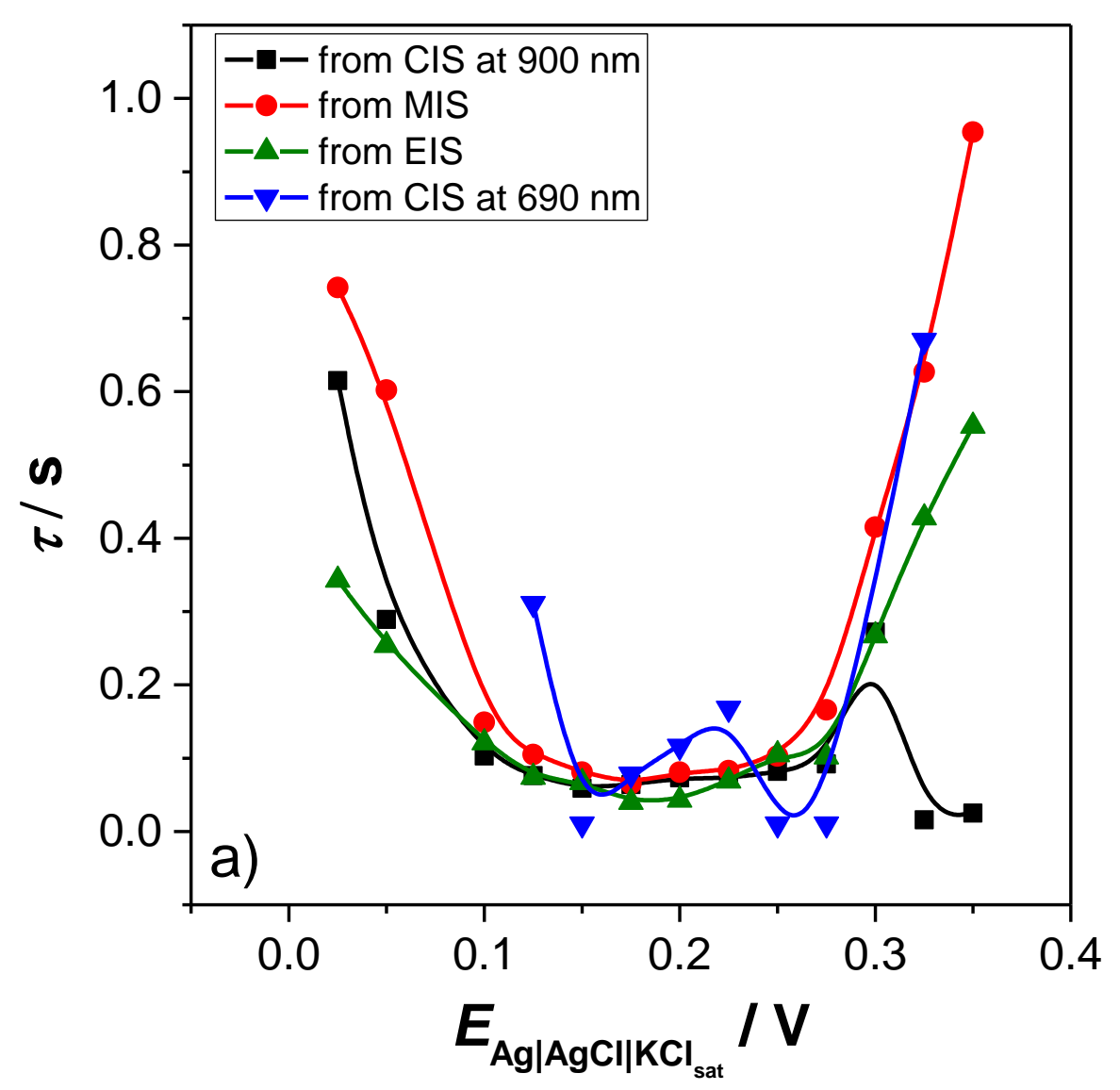




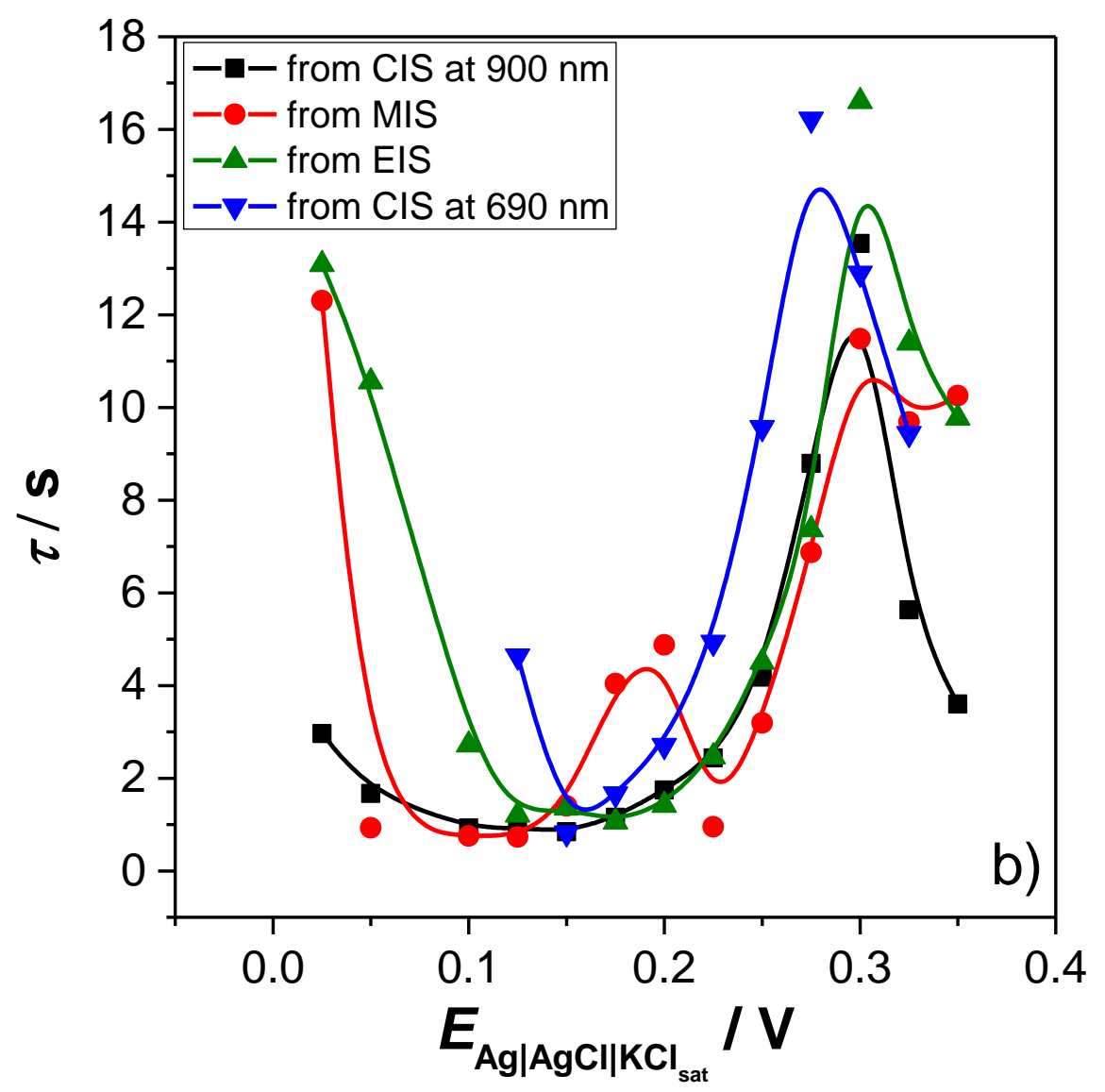

Figure 4. Evolution of the time constant, $\tau$, for the fast process (a) and slow process (b) obtained by fittings of EIS, MIS and CIS at $690 \mathrm{~nm}$ and at $900 \mathrm{~nm}$ for a PB film deposited on a gold electrode in a $0.5 \mathrm{M} \mathrm{NH}_{4} \mathrm{Cl}$ acid solution $(\mathrm{pH}=3.0)$. The solid lines are guides to the eye. 


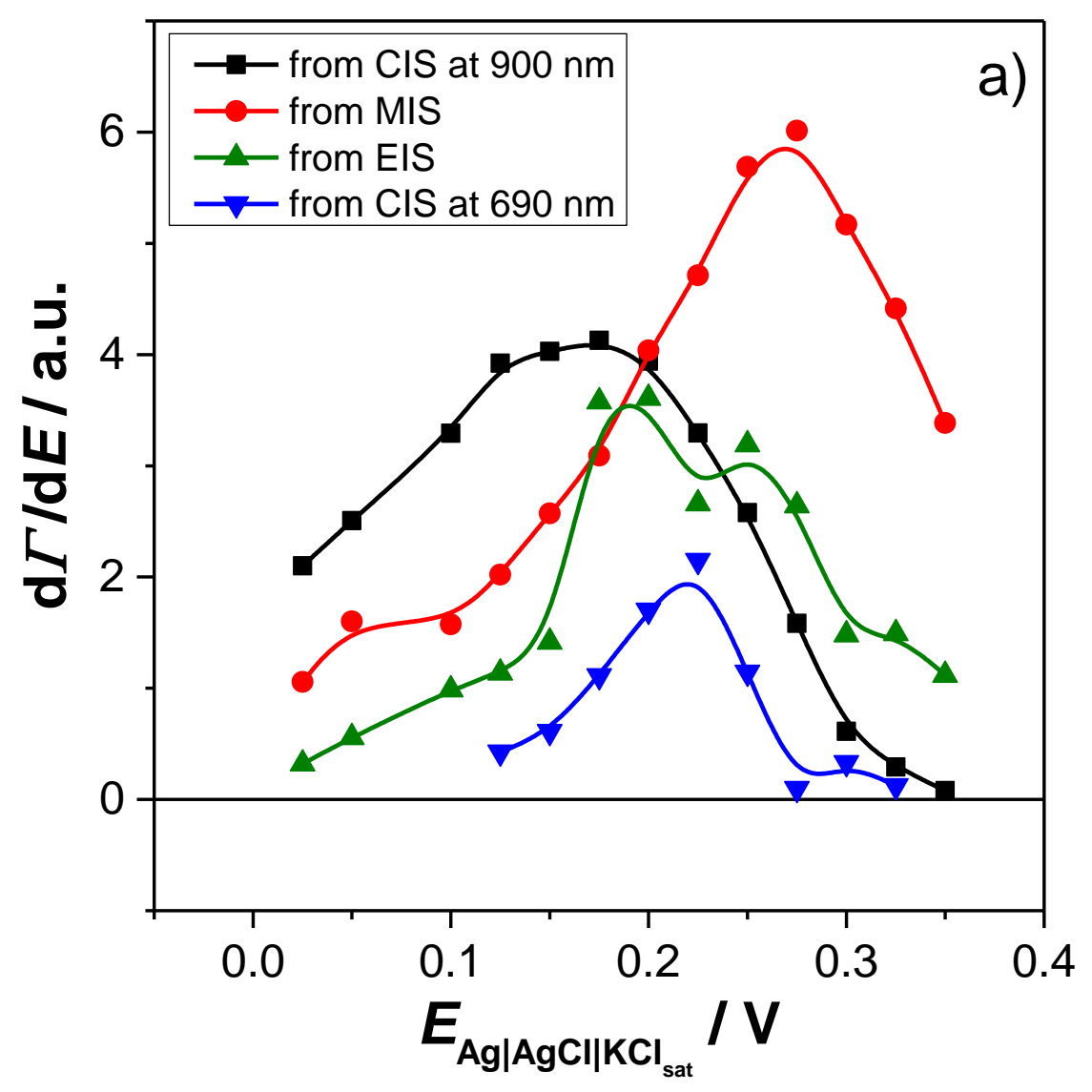




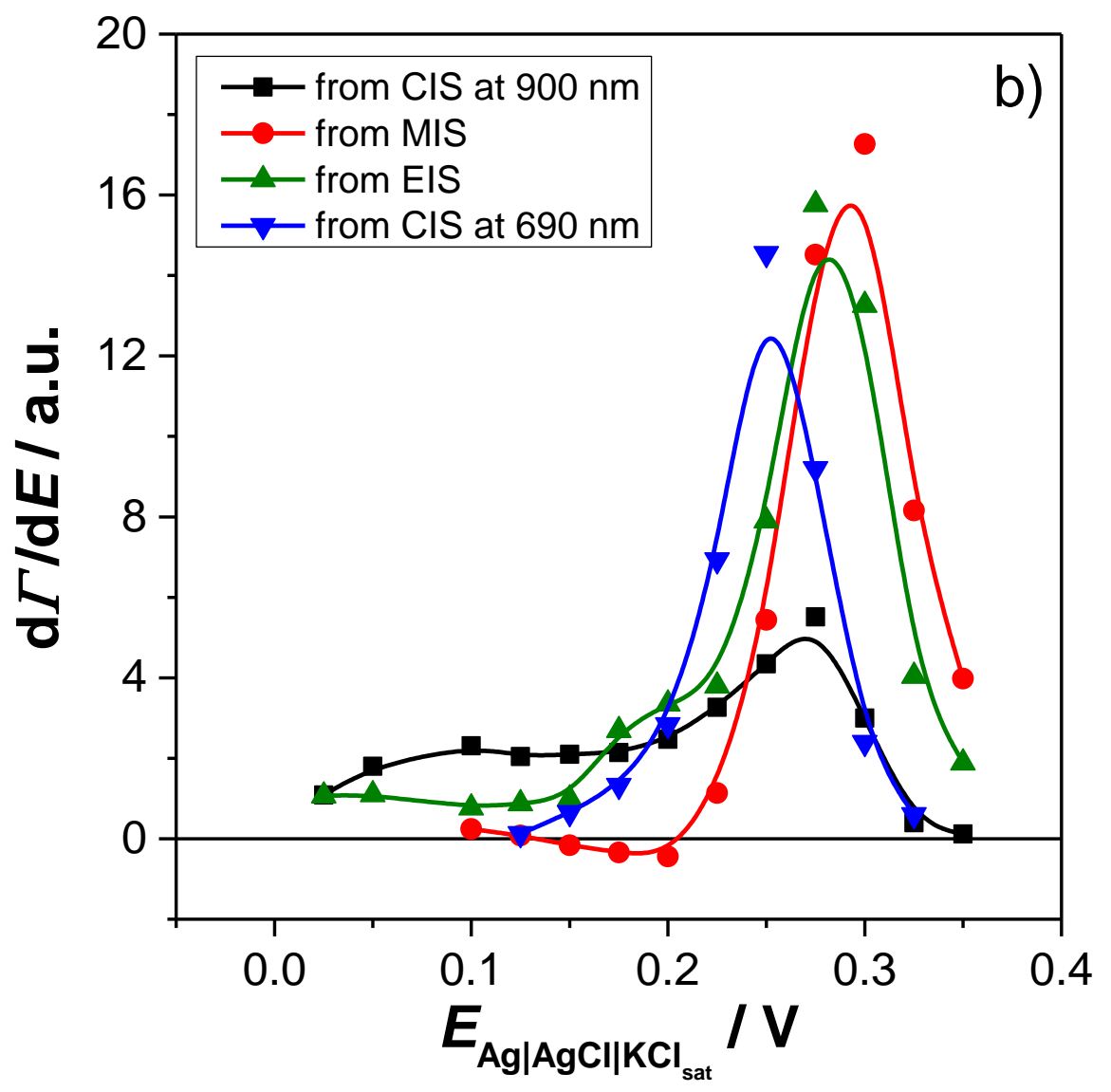

Figure 5. Evolution of the derivative of the insertion law, $\mathrm{d} \Gamma / \mathrm{d} E$ (normalized values), for the fast process (a) and slow process (b) obtained by fittings of EIS, MIS and CIS at $690 \mathrm{~nm}$ and at $900 \mathrm{~nm}$ for a PB film deposited on a gold electrode in a $0.5 \mathrm{M} \mathrm{NH}_{4} \mathrm{Cl}$ acid solution $(\mathrm{pH}=3.0)$. For better comparison, EIS, MIS and/or CIS data series were multiplied by an appropriate factor. The solid lines are guides to the eye. 


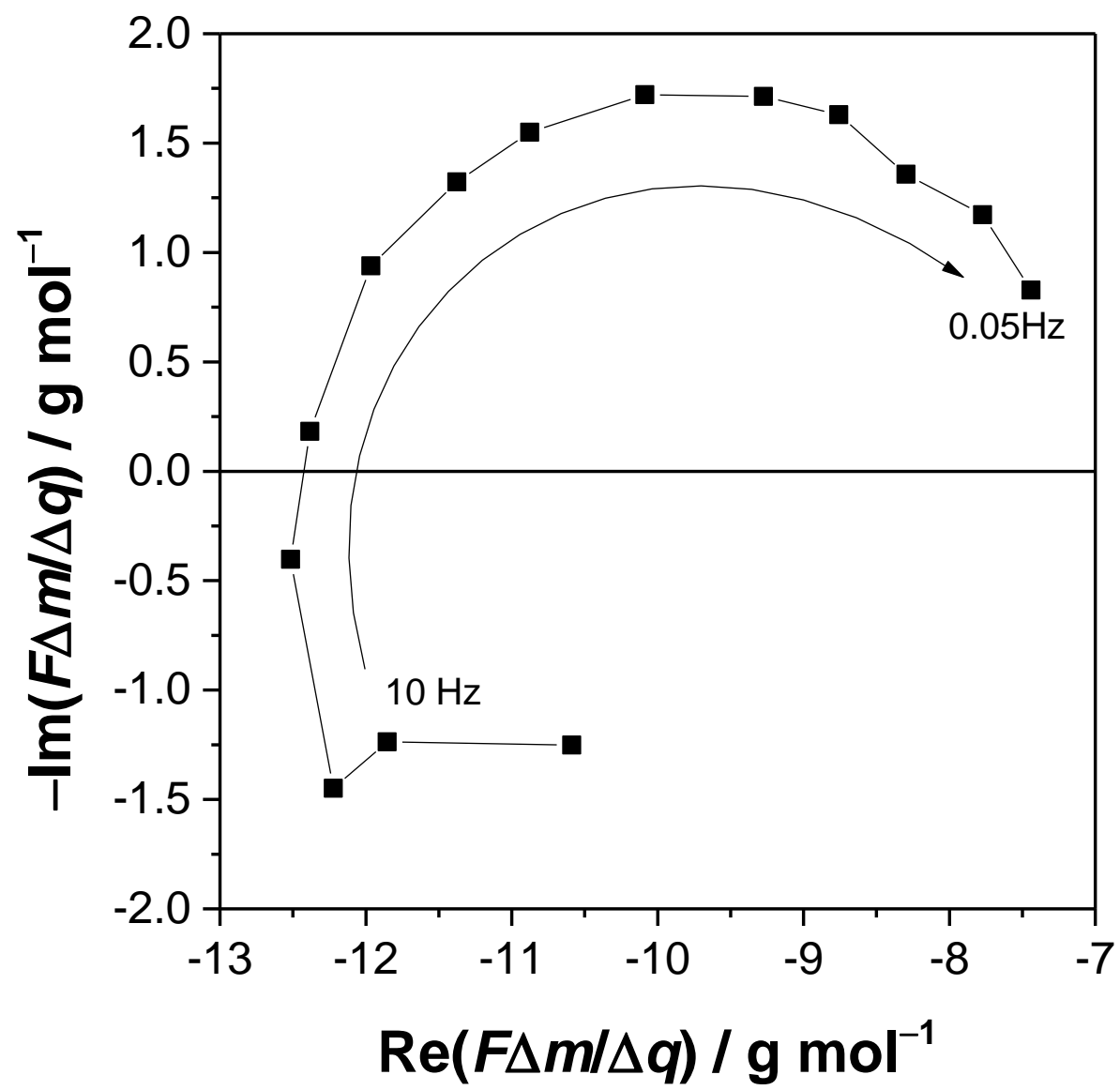

Figure 6. $F \Delta m / \Delta q$ crossed impedance functions at $0.15 \mathrm{~V}$ for a $\mathrm{PB}$ film deposited on a gold electrode in a $0.5 \mathrm{M} \mathrm{NH}_{4} \mathrm{Cl}$ acid solution $(\mathrm{pH}=3.0)$. 


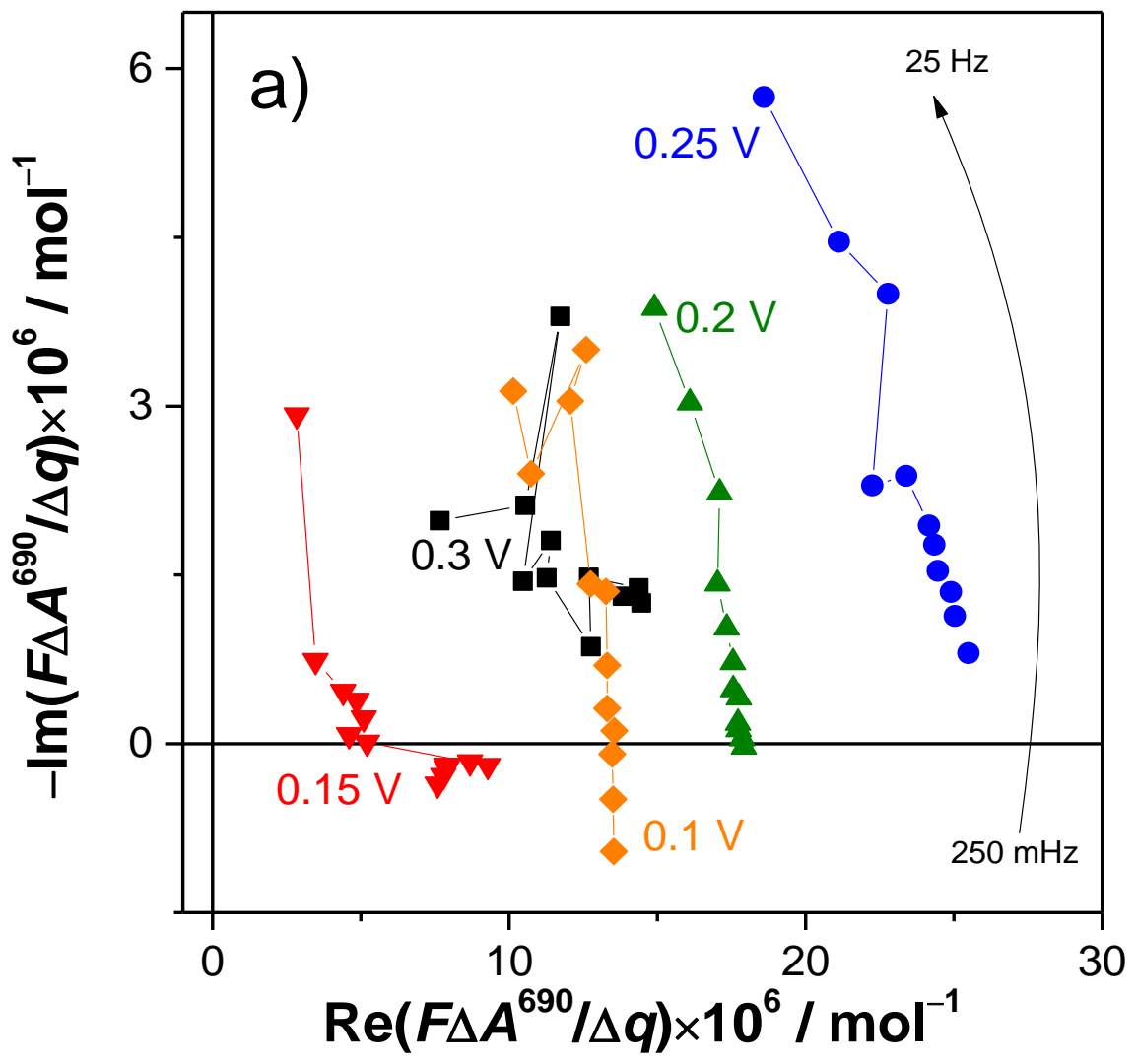




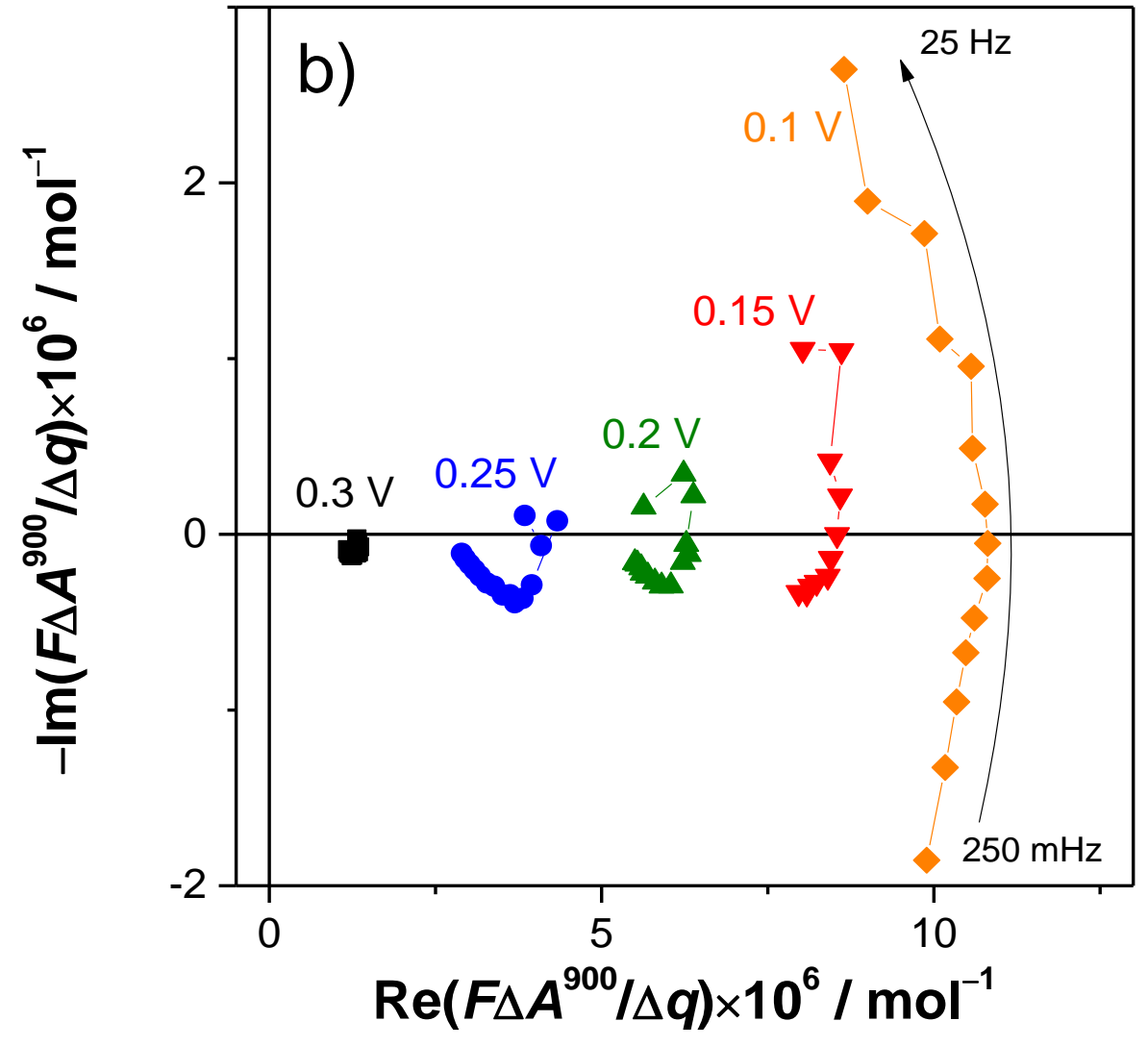

Figure 7. $F \Delta A^{690} / \Delta q(\omega)$ (a) and $F \Delta A^{900} / \Delta q(\omega)$ (b) crossed impedance functions at different polarization potentials for a $\mathrm{PB}$ film deposited on a gold electrode in a $0.5 \mathrm{M} \mathrm{NH}_{4} \mathrm{Cl}$ acid solution $(\mathrm{pH}=3.0)$. 